\title{
The Exploration of Enterprise E-Commerce Intelligence System
}

\author{
Li Dehui \\ School of Economics and Management \\ South China Normal University \\ Guangzhou, China \\ lidehui@m.scnu.edu.cn
}

\begin{abstract}
Enterprise e-commerce intelligence system, which is used in the e-commerce enterprise to carry on the information processing and the information mining, has gradually become the key factor that decides the e-commerce enterprise`s competition ability. This paper explores the enterprise electronic business intelligence system in 6 aspects. The enterprise e-commerce intelligence system is formed of the enterprise network system, the enterprise management information system, the enterprise e-commerce website and the enterprise competitive intelligence system. And its functions are determined by these 4 parts, such as supply chain management, financial management, sales management, production control and management, customer management, logistics management, enterprise knowledge management, electronic banking, cargo transfer, monitoring the environment, mining the market opportunities and the threats, the analysis of reality competitors and potential competitors, crisises expecting and intelligence forecast, technical and business tracking, strategy development and security and other functions etc. The key techniques are OLAP, OLTP, database, personalized recommendation, data mining, data warehouse, visualization etc. This research provides useful reference for the construction and the researching of the enterprise ecommerce intelligence system.
\end{abstract}

Keywords-E-commerce; Intelligence System; Competitive Intelligence; Business Intelligence;Information Technology

\section{INTRODUCTION}

E-commerce, as an industry that grown up relying on information technology, is rapidly developing. With the development of electronic commerce, information continues to expand, the complexity of the information also increases. In the three basic elements of the world, such as information, material and energy, the information comes in the first place. The ability to process and utilize the information becomes a key determinant of the competitiveness of enterprises. E-commerce system, which is a computer system based on the Internet and other networks, aims at completing the e-commerce activities and achieve business objectives, meets the needs of production, sales, service, production and management, and supports the enterprise's foreign business collaboration, improves the enterprise's level of information from operation, management and decisionmaking and other enterprise-level comprehensively, and provides business intelligence for enterprises.

Traditional e-commerce system focuses only on the information processing, but do not focus on the more important aspects of the use of information mining.
Business intelligence is the wisdom and ability that enterprises use the modern information technology to collect, manage and analyze structured and unstructured business data and information, the creation and the cumulative business knowledge and insights are to improve business decision-making, effective business operations, improve various business processes, enhance all aspects of business performance, and enhance the overall competitiveness. This paper studies the enterprise e-commerce intelligence system, whcih is an intelligent information system that based on the enterprise ecommerce system, combined with further business intelligence technology and enterprise competitive intelligence system to enhance the level of enterprise information and decision support capabilities.

There are few people who study the enterprise ecommerce intelligence system currently. Using the "ecommerce intelligence system" as keywords to do the fulltext search in the Chinese National Knowledge Infrastructure (CNKI), there are few matching items. If searching the same keywords in the Baidu, there is also few matching results. Therefore, this study is a certain degree of innovation.

\section{THE STRUCTURE OF ENTERPRISE E-COMMERCE INTELLIGENCE SYSTEM}

Throughout the development process of the information system, in the beginning is the transaction processing system that faces to the daily transaction processing, and gradually develops into the senior management information system that selectively provides status information to the business managers and executives, and then develops into the management information system that faces to all managers, the next stage is the decision support system that assists decisions makers to make decisions. The next one is the enterprise competitive intelligence system, which can collect, store, process, analyze the intelligence information from the enterprises themselves, competitors and business' external environment. Advanced Information systems is enterprise e-commerce intelligence system, the integration of business intelligence technology, competitive intelligence system and e-commerce system. 


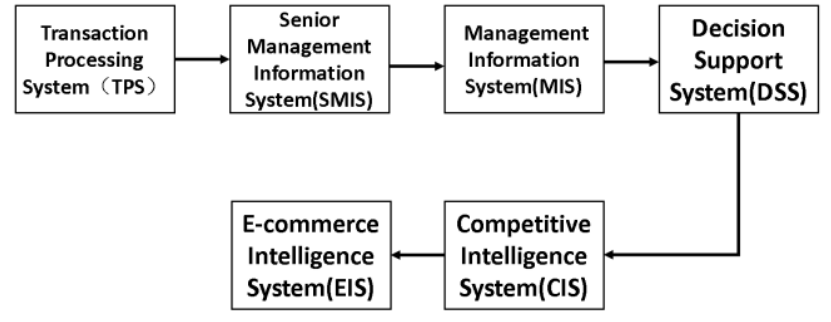

Figure 1. The development process of the information system.

Enterprise e-commerce intelligence system is based on the enterprise network system, connects the enterprise management information system, enterprise e-commerce system and enterprise competitive information system. Therefore the enterprise e-commerce intelligence system is a form of the following four parts: the enterprise network system, the enterprise management information system, the enterprise e-commerce website and the enterprise competitive intelligence system.

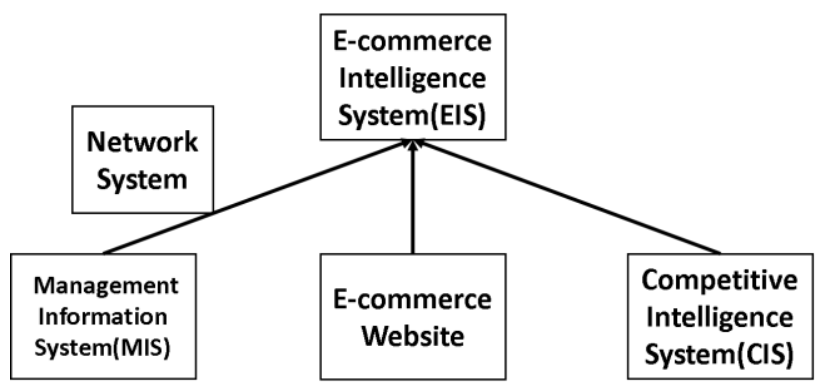

Figure 2. The structure of enterprise e-commerce intelligence system.

\section{A. The Enterprise Network System}

The enterprise network system is the basis of enterprise e-commerce intelligence system. The enterprise management information system, enterprise e-commerce system and enterprise competitive information system are connected by it. Enterprise network system is divided into the Intranet, the Extranet and the Internet. Intranet is the Internet technology mechanism implementation in the enterprise. On one hand, it absorbs the advanced Internet network technology`s advantages. On the other hand, due to security considerations, through a firewall to separate the internal network and the Internet, the enterprise network system makes itself more secure and reliable. Extranet refers to a dedicated security network on the formation of the Internet, it aims at connecting the enterprise's Intranet and its business partners' Intranet more security, sharing the information resources between enterprise and its trading partners. And the Internet is the biggest inter-network in the world. That is a huge network connection that is formed by networks. Through the Internet, enterprise can disclose its own information to the outside world and connect with the mass-market customers.

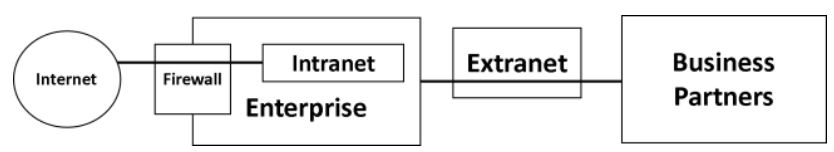

Figure 3. The structure of enterprise network system.

\section{B. The Enterprise Management Information System}

The enterprise management information system is a complex system that covers the all activities of the enterprise's production, operation and management. It plays the collecting, processing, storing and transmitting the information roles in the organization, it also supports the decisions making and the commanding of the organization. The enterprise management information system is combined with enterprise resource plan system (ERP system), customers relationship manage system (CRM system), knowledge manage system (KM system), sales manage system, logistics manage system and other systems, it is throughout the whole management process of the enterprise.

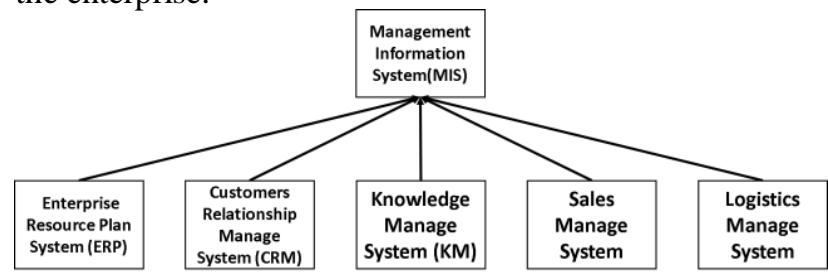

Figure 4. The structure of management information system.

\section{The Enterprise E-Commerce Website}

On the basis of the Internet, the enterprise e-commerce website provides information about the goods or services to different users through the website and offers convenient to the users by integrating the purchasing, delivering, paying and other systems according to the properties of the commodities. It can reduce the costs. The customers, suppliers, and other business partners can get the enterprise's information and operate the business activities in its enterprise e-commerce website. The enterprise e-commerce website connects the markets' information with the enterprise management information system as well, this function can transmit the information of the market-requirement into the enterprise management information system, so the enterprise can adjust its marketing, operating and managing activities according to the changes of the markets.

\section{The Enterprise Competitive Intelligence System.}

Competitive information is the information and the research about the competitive environment, competitors, competitive situation and competitive strategies, it plays a very important role in today's intelligence age. Competitive intelligence system is led to human intelligence and formed information networks. It aims at enhancing the enterprise's competitive abilities. It is a human-computer system that combines with competitive strategy decision system and consult system. Competitive intelligence system provides strong intellectual support and intelligence support for enterprises to gain competitive advantages.

\section{THE FUNCTION OF THE ENTERPRISE E- COMMERCE INTELLIGENCE SYSTEM}

Because the enterprise e-commerce intelligence system is formed of enterprise network system, enterprise management information system, enterprise e-commerce website and enterprise competitive intelligence system, its functions are decided by these four systems' functions. 
The enterprise network system provides the connect function. The enterprise management information system provides the functions of supply chain management, sales management, financial management, production control and management, customer management, logistics management, enterprise knowledge management. The enterprise e-commerce website provides the functions of advertising, consultation talks, online ordering, online payment, electronic banking, cargo transfer, consultation and business management. The enterprise competitive intelligence system offers the functions of monitoring the environment, mining the market opportunities and the threats, the analysis of reality competitors and potential competitors, crisises expecting and intelligence forecast, technical and business tracking, strategy development and security and other functions.

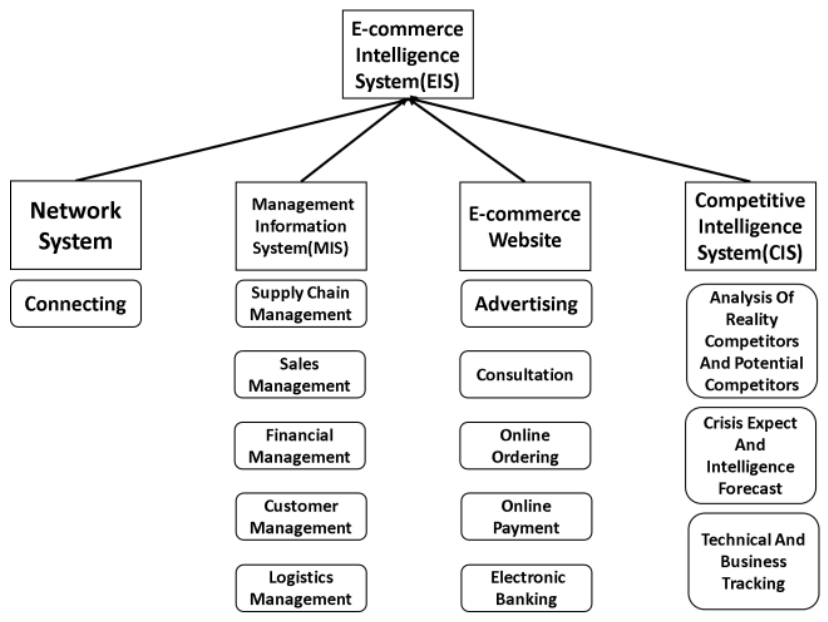

Figure 5. The functions of enterprise e- commerce intelligence system.

\section{THE KEY TECHNIQUES OF THE ENTERPRISE E- COMMERCE INTELLIGENCE SYSTEM}

Because the enterprise e-commerce intelligence system is based on the enterprise network system, its basic key techniques are internet, intranet and extranet techniques. The key techniques applied in the enterprise e-commerce website and the enterprise management information system are online transaction processing (OLTP), database techniques, multi-media techniques etc. The enterprise ecommerce website also widely uses personalized recommendation technology and takes the initiate to provide users interested information resource based on the users' personalized information. Business intelligence includes data mining, data warehouse, online analysis process, visualization, knowledge management, intelligent search, metadata technology and other technologies, these techniques are mainly used in the enterprise competitive intelligence system.

\section{THE SER VICE USERS AND USER INTERFACES OF THE ENTERPRISE E- COMMERCE INTELLIGENCE SYSTEM}

In terms of the service users and user interfaces, different components of enterprise e-commerce intelligence systems serve different users, so the user interfaces designs are also vary accordingly.

The enterprise management information system services in various functional departments within the enterprise, and the competitive intelligence system services competition intelligence analysts and decision makers within the enterprise. Since these two systems are oriented to internal staffs, the user interfaces are needed to be designed into simple, clear and easy to use.

The enterprise e-commerce website serves the customers, suppliers and other cooperators, as a platform for representatives of enterprise image and help enterprise earnings, its user interfaces do not only need to be designed into easy to use, but also need to be designed into pretty and humanized.

\section{THE DATA SOURCE AND THE DATA PERFORMANCE} OF THE ENTERPRISE E- COMMERCE INTELLIGENCE SYSTEM

In terms of data source, the data used by the enterprise e-commerce intelligence system comes from the inside and the outside of the enterprise. The internal data of the enterprise mainly comes from the enterprise's different functional departments' operation data, such as sales data, financial data, production data, logistics data, customer data, investment data, product data etc. In terms of the external data sources, the enterprise management information system's outside data mainly comes from the enterprise's customers demand information, suppliers' supply information and other partners' cooperation information etc. The enterprise e-commerce website's external data mainly comes from the visitors of the website, including the information reflected by the customers, suppliers and other cooperators. The external data source of the enterprise competitive intelligence system is more widely, except the customers, suppliers and the cooperators, it comes from competitors, government departments and social organizations.

In terms of the data performance, the enterprise management information system and the enterprise ecommerce website need to process mass transactions, and they face to the enterprise functional departments, suppliers, cooperators and customers, so they have high requirements in data processing speed and data accuracy, their data is based on the real-time data and it updates frequently. However, the competitive intelligence system services competition intelligence analysts and decision makers, its data is highly comprehensive analysis of large fuzzy data. So it doesn't have high requirements in data processing speed and data accuracy, it based on the historical data and it updates unfrequently.

\section{CONCLUSIONS}

The enterprise e-commerce intelligence system is consisted of enterprise network system, enterprise management information system, enterprise e-commerce website and enterprise competitive intelligence system, so its functions are decided by these four systems functions: supply chain management, sales management, financial management, production control and management, customer management, logistics management, enterprise knowledge management etc. And it runs more efficient and powerful than these systems which run independently. The key techniques of the enterprise e-commerce intelligence system are OLTP, database, multi-media, data mining, data warehouse, OLAP and visualization.

With the continuous development of e-commerce, ecommerce intelligence system will be popularized in future 
large-scale e-commerce companies. More advanced technologies and concepts will be applied to business ecommerce intelligence system. Application of the ecommerce intelligence system with advanced degree or not of the enterprise will be the determine competitiveness core elements of the future enterprises. This paper just studies the enterprise e-commerce intelligence system in theory, hoping to provide a reference for the construction and subsequent study of the enterprise e-commerce intelligence system.

\section{REFERENCES}

[1] Wang Hongliang, Zhang Qi, Zhu Yantao, Competitive Intelligence System Model Construction of Big Data Environment for SMEs, Information Studies:Theory \& Application, Vol 07, 2015, pp. 109114, doi:10.16353/j.cnki.1000-7490.2015.07.021.

[2] Guan Sifa, Li Zongjie, The Enlightenment of Competitive Intelligence in Amercia, Library and Information Service, Vol 04, 2015,pp.83-92,doi: 10.13266/j.issn.0252-3116.2015.04.013.

[3] Wang Xin, The Reconstruction of Enterprise Competitive Intelligence System Based on The Big Data, Hei Longiiang University:pp.23-24.
[4] Guan Sifa, Li Jinhua, Liu Qi, The Construction of The Enterprise competitive intelligence System, Information Science, 2014,pp.4753,doi: 10.13833/j.cnki.is.2014.01.002.

[5] Huang Xiaobin, Zhong Huixin, The Construction of The Enterprise Competitive Intelligence System Based on Big Data, Journal of Intelligence, March 2013,pp.37-43.

[6] Li Jiang, Tang Yan, The Research of Reverse Logistics Enterprise Competitive Intelligence System Based on the Internet of Things, Journal of Intelligence,, October 2011,pp.151-155.

[7] Yu Wenting, Wu Dan, The Exploration of Collaborative Business Intelligence System, Journal of Information Resources Management, 2015,pp.49-57,doi: 10.13365/j.jirm.2015.03.049

[8] Niu Xiaojun, The Thinking of The Business Intelligence System, China Management Informationization, Vol 23, 2011, pp.66-67.

[9] Yi Cong, The Research of The Enterprise Competitive Intelligence System Based on Web Mining, South China University of Technology, 2011, pp.20-22.

[10] Su Xinning, The Design of The Competitive Intelligence System in Internet, Information Studies:Theory \& Application, Vol 08, 2010, pp.104-108.

[11] Sun Ke, The Research of The Interface Design of The Manage Information System, Dalian University of Technology, 2010, pp.32-34. 